\title{
Las transformaciones urbanísticas como recurso pedagógico para el estudio de la historia local de Córdoba, en la formación del futuro profesorado de Educación Primaria
}

Urban planing transformations as a pedagogical resource for the study of local history of Cordoba, in the formation or the future teacher or Primary Education

\author{
Dr. Miguel Jesús LÓPEZ SERRANO \\ Universidad de Córdoba. \\ mjlopez@uco.es \\ Dr. Rafael GUERRERO ELECALDE \\ Universidad de Córdoba. \\ rgelecalde@uco.es
}

\begin{abstract}
Resumen: La imagen que tenemos del pasado en muchas ocasiones es una idea confusa y con múltiples acepciones. Normalmente solemos entenderlo como un recurso que pertenece al patrimonio de las personas y las sociedades a lo largo de la historia. Así pues, se hace perentoria la necesidad de que los futuros docentes estén capacitados y capacitadas tanto en materias transversales u optativas de Educación Medioambiental como en la consecución de los objetivos de etapa, área y los contenidos de las diferentes asignaturas que contribuyan a explicar y comprender el concepto del pasado más reciente a través de propuestas didácticas en el alumnado.
\end{abstract}

Abstract: The image we have of the past on many occasions is a confusing idea and with multiple meanings. Normally we tend to understand it as a resource that belongs to the heritage of people and societies throughout history. Thus, the need for future teachers to be trained in both transversal or optional subjects of Environmental Education and in the achievement of the objectives of stage, area and the contents of the different subjects that contribute to explain and understand becomes urgent. the concept of the most recent past through didactic proposals in the students. 
Palabras clave: Urbanismo, Ciencias Sociales, Historia, Educación Primaria, Córdoba.

Keywords: Urbanism, Social Sciences, History, Primary Education, Córdoba.

\section{Sumario:}

I. Introducción.

II. El urbanismo en la provincia de Córdoba.

III. Las transformaciones acometidas 1868-1885.

3.1. Alineación, configuración y reforma de calles.

IV. Conclusiones.

V. Bibliografía.

Recibido: septiembre 2020.

Aceptado: noviembre 2020. 
En los últimos decenios la importancia del estudio y enseñanza de nuestro pasado más reciente desde una perspectiva localista y sus posibles transformaciones ha sido un tema fundamental en las reuniones educativas más vinculantes. La Universidad no ha estado ajena a esta realidad y ha ido incorporando a su oferta académica diferentes grados, a la vez que, las asignaturas de conceptualización didáctica específica han pasado a formar parte de los planes de estudio de varias titulaciones.

La imagen que tenemos del pasado en muchas ocasiones es una idea confusa y con múltiples acepciones. Normalmente solemos entenderlo como un recurso que pertenece al patrimonio de las personas y las sociedades a lo largo de la historia. Un legado de carácter histórico, ambiental y social que requiere una atención por parte no solo de la comunidad científica o de las élites gubernamentales, sino de las políticas educativas que tienen la obligación de dotar su estudio con una serie de contenidos sólidos ya que, el estudio y comprensión de los vaivenes políticos y urbanísticos, en sí mismos, son una herencia, un bien común de las sociedades que debe ser enseñado desde las edades más tempranas para entender las diferentes transformaciones que han sufrido a lo largo de la historia.

Teniendo en consideración estas modificaciones, las más destacables están en relación con aspectos variables y casuísticas diversas, podemos enfatizar como elementos reformadores del entramado urbanístico y político las causas económicas que derivan en gran medida de las actuaciones políticas de las distintas administraciones, las causas naturales: incendios, deforestaciones, o en el caso que nos ocupa, la planificación y construcción de políticos y elementos destacables acaecidos a finales del S. XIX en la ciudad de Córdoba.

Así pues, se hace perentoria la necesidad de que los futuros docentes estén capacitados y capacitadas tanto en materias transversales u optativas de Educación Medioambiental como en la consecución de los objetivos de etapa, área y los contenidos de las diferentes asignaturas que contribuyan a explicar y comprender el concepto del pasado más reciente a través de propuestas didácticas en el alumnado. A lo largo de la Etapa Primaria, los y las estudiantes deben ir 
comprendiendo a la vez que estableciendo las primeras nociones de relación e importancia entre los acontecimientos y los elementos que interactúan en el entorno natural, social, político... Por tanto, este tema va a estar interrelacionado con el área de la Didáctica de las Ciencias Sociales, de la Geografía, entre otras, puesto que su objetivo principal será el de estudiar y comprender los principales elementos y transformaciones de la sociedad, el territorio o paisaje natural.

Es por ello que creemos que la enseñanza del entorno debería comenzar desde las edades más tempranas y continuar en las diferentes etapas del sistema educativo español. Se debería motivar no solo al alumnado de los grados de Maestro de Educación Infantil y Primaria, sino también a los pequeños y pequeñas, con el objetivo de que puedan estudiarlo, vivenciarlo y que desarrollen una serie de estrategias que les faculten un entendimiento progresivo, comprendiendo que el respeto hacia los distintos ecosistemas y al cuidado del medio ambiente debe ser un eje vehicular de su formación académica y personal.

Recogemos en estas líneas el fundamento teórico para realizar una futura propuesta didáctica que tenga como objetivo la enseñanza, desde el punto de vista histórico, de las modificaciones urbanísticas y las cuestiones políticas de nuestro pasado más reciente, como elemento transformador del paisaje o entorno más cercano.

Proponemos un esbozo documental sobre las diferentes actuaciones existentes en Córdoba y su provincia, para así tener el sustrato con el que elaborar una serie de prácticas educativas (itinerarios, mapas históricos...) con el que, los futuros docentes, puedan entender la importancia del paisaje urbano, no solo como pilares económicos, sociales etc., sino también como elementos trasformadores y configuradores de nuestro territorio.

\section{INTRODUCCIÓN}

Los casi 7 años que transcurren entre la caída de Isabel II y la proclamación de Alfonso XII son un lapso de inestabilidad, y tan sólo la inercia de algunos lentos procesos urbanos y territoriales impide considerar dicha fase, a efectos de historia, como verdadero tiempo muerto en nuestra provincia, así como, en el resto del país ${ }^{1}$.

\footnotetext{
${ }^{1}$ MONTERO VALLEJO, M., y DE TERÁN, F., Historia del Urbanismo en España: Siglos XIX y XX, Madrid 1999, pp. 91-92.
} 
Como es harto sabido en España, el retraso industrial durante el siglo XIX evitó el nacimiento de las ciudades carbón, desarrolladas en la Europa industrial y en los Estados Unidos. La cada vez mayor concentración de la población en las urbes dio lugar a una escasez de viviendas y al descenso de las condiciones de vida ya que, en ausencia de grandes concentraciones de obreros industriales, estrictamente hablando, se trataba más bien de una población artesana, la propia vivienda servía a la vez de taller para sus trabajos ${ }^{2}$.

Después de las guerras napoleónicas, la población española inició un proceso de crecimiento ininterrumpido que le hizo llegar hasta los 20 millones de habitantes en tan solo siglo y medio, reflejándose tal fenómeno especialmente en las ciudades. La población conservaba una estructura preindustrial y en un primer momento se produjo la degradación de las condiciones de vida de la población urbana. La ciudad surgida de este proceso presentaba una grave situación de hacinamiento y de crisis en los servicios.

La aglomeración de los habitantes en las ciudades fue consecuencia de un crecimiento demográfico constante unido a una falta de aumento paralelo del número de viviendas. Desde finales del siglo XVIII, el crecimiento poblacional de los grandes núcleos se realizó a costa del número de personas por vivienda y de la aparición de realquilados. La subdivisión de las antiguas residencias unifamiliares, la elevación de pisos, la ocupación para hogares de la superficie de la parcela anteriormente sin edificar, la utilización de una parte del espacio de las calles mediante la proliferación de voladizos contribuyeron a densificar gravemente el caótico casco urbano de unas ciudades que mantienen la trama viaria heredada de tiempos anteriores y en las que la pauta común era la existencia de las calles de menos de cuatro metros de anchura.

No será hasta la segunda mitad del siglo XIX cuando aparezcan los primeros planes de ensanche y de reforma interior con un mínimo de organización, pudiéndose hablar desde ese momento del comienzo del urbanismo nuevo peninsular. En la centuria decimonónica se distinguen tres generaciones ${ }^{3}$ : la fernandina, la isabelina y la de la Restauración. Esta última se prolonga a lo largo del primer tercio del siglo XX, es el periodo en el que realmente empieza

${ }^{2}$ HERNANDO, J., Arquitectura en España 1770-1900, Madrid 1989, pp. 45- 48.

${ }^{3}$ La generación fernandina es una continuación del siglo XVIII. Su trazado responde a una cuadrícula de dimensiones muy reducidas, cruzada por algunas diagonales que unían las plazas. Las avenidas ofrecen perspectivas largas, lo que demuestra la influencia barroca. En la etapa isabelina se experimenta una auténtica fiebre por la construcción de mercados cubiertos, se derribaban conventos para construir mercados como signo de progreso popular urbanístico. Tanto en la época de Fernando VII como en la de Isabel II se produce una importante obra de reconstrucción, apareciendo construcciones modernas de 4 y 5 pisos en las ciudades más importantes. 
la actividad urbanística entendida como actualmente. De esta fase datan las primeras Ordenanzas Municipales de edificación y la aparición de los Planes de Ensanche de Córdoba ${ }^{4}$. Las actuaciones urbanísticas en esta etapa son más de carácter expansionista que de saneamiento, reforma interior o eliminación de barrios insalubres. Sólo a finales de siglo se impondrá una visión sanitaria del urbanismo.

Los problemas derivados de la superpoblación de las ciudades generan la necesidad de ofrecer una respuesta específica, surgiendo entonces técnicas urbanísticas personalizadas a los posibles problemas. No obstante, conviene hacer constar que en España la llegada tardía de la revolución industrial, a finales del primer tercio del siglo XIX, y la existencia de grandes espacios urbanos libres en el interior de las ciudades (huertos, patios) introduce ciertos matices en relación con las circunstancias que concurren en otros países como Gran Bretaña o Francia, con el nacimiento casi instantáneo de las capitales industriales. En un principio, la actuación de los organismos públicos se centró esencialmente en la puesta en práctica de los llamados poderes de policía urbana, los cuales, a su vez, actuaban mediante la regulación en ordenanzas locales de las condiciones de las nuevas construcciones.

\section{EL URBANISMO EN LA PROVINCIA DE CÓRDOBA}

La planimetría existente a mediados del siglo XIX en la ciudad de Córdoba responderá al modelo heredado del urbanismo bajomedieval cristiano, configurador del entramado de uno de los cascos históricos más grandes de toda España, con 220 has $^{5}$, que, desde tiempos de la Reconquista, se mantendría casi en exclusividad, exceptuando algunas intervenciones mínimas que no llegaron a transformar su morfología, hasta la desaparición del recinto amurallado.

4 "La idea del «Ensanche de Poblaciones», concebida a mediados de siglo y respaldada por sucesivas leyes $(1864,1876$ y 1892), proporcionó un instrumento tan innovador como eficaz para organizar el crecimiento de las ciudades españolas, desde la perspectiva del pensamiento liberal y en sintonía con el resto de Europa. Los ensanches representaron el mayor esfuerzo de modernización en época contemporánea y una reflexión global sobre todas las dimensiones del hecho urbano, especialmente en los proyectos más tardíos, que encierran mucho de lección aplicable a la realidad actual. Al ser llevados a la práctica, aunque fuera muy lentamente y con desfiguraciones importantes, en ciudades cuya escala salta desde Madrid o Barcelona hasta León, Alcoy o Laredo, protagonizarían el proceso urbano durante más de medio siglo, resultando la principal concreción formal del nuevo orden capitalista”, DE TERÁN, M. y SOLÉ I SABARÍS, LL., Geografia general de España, Barcelona 2009, vol. I, p. 258.

${ }^{5}$ GARCÍA VERDUGO, F. R., "La intervención urbanística en el casco histórico de Córdoba: la manzana de Orive", en II Jornadas de Geografia urbana: Recuperación de centros históricos, utopía, negocio o necesidad social; La Geografia de la Percepción como instrumento de planeamiento urbano y ordenación; Las fachadas urbanas, marítimas y fluviales, 1995, p. 129. 
Hasta entonces las modificaciones de la trama urbana cordobesa estuvieron ocasionadas por los alineamientos ${ }^{6}$ realizados en algunas de sus calles, y, fundamentalmente, por los cambios que se produjeron en diversas plazas que la transformaron bien macizándolas o bien abriéndolas como consecuencia de la desaparición/apertura de algunas de ellas. También contribuyó a modelar la imagen de la ciudad en este siglo la construcción de múltiples casas nobiliarias, edificios religiosos y benéfico-asistenciales, conventos y hospitales que ayudarían a cambiar la fisonomía estética de la urbe. Junto a estas transformaciones también es significativa la urbanización del barrio del Alcázar Viejo, acaecida a finales del siglo XIV, que tiene lugar en el ángulo suroccidental de la villa y que sigue parámetros propios del urbanismo cristiano.

Será en la segunda mitad del siglo XIX cuando el casco antiguo de la capital sufra una mayor alteración en su tradicional trazado urbano. Las desamortizaciones y los caprichos de la burguesía fueron los dos elementos fundamentales que posibilitaron estas transformaciones; las primeras al liberar dentro de la ciudad grandes predios (edificios, huertos, etc.) que anteriormente habían integrado las propiedades desamortizadas. De cariz totalmente diferente nos encontramos con el nuevo status económico adquirido por las clases dominantes, quienes para reflejar dicho poder proponen una ciudad más dinámica, abierta y racional que la vieja ciudad heredada del pasado, y en la que esta nueva clase social emergente pudiera exhibir convenientemente su prestigio económico.

La intervención burguesa en la ciudad se tradujo fundamentalmente en la realización de una serie de operaciones de ensanche que se plasmaron

6 "Nada más bello ni que más hermosee una población manifestando su mayor o menor grado de cultura que un acertado sistema de alineaciones; por este motivo se consigue mayor salubridad en su reciento porque se facilita la ventilación y el que en una población se respire una atmósfera saludable es el principal objetivo a que debe atender toda corporación municipal. No es esta sola la utilidad que reporta un buen entendido sistema de alineaciones y aunque no de tanta importancia sin embargo no son de menos notar las siguientes: Da seguridad en la vía pública, objeto que no debe descuidar una diligente administración a quien particularmente está encargado de velar por la seguridad individual. Destierra las irregularidades y defectos de que por lo general están recargadas las calles de la mayor parte de las poblaciones, particularmente las que son de antigua fundación. Aumenta en gran manera el valor de los solares que siempre está en relación con la importancia y buena disposición de la vía pública. Presta facilidades en las comunicaciones internas de la población y, finalmente, la administración encuentra en ello una gran ventaja y es que una vez aprobado el plano general de alineaciones se evade de la infinitud de pretensiones de interés privado de que generalmente se ve acosada. La construcción de edificios de nueva planta y la reedificación de los antiguos puede dar pábulo a pretensiones abusivas, ya queriendo ocupar terrenos que pertenecen a la vía pública, ya queriendo evadirse porque así lo juzga convenientemente, y no pocas veces da lugar a conflictos de consideración por las arbitrarias determinaciones de la autoridad municipal [...]”, AMCO. Sección $8^{\mathrm{a}}$, serie $5^{\mathrm{a}}$, leg. 29, Alineaciones de calles, agosto de 1868. 
principalmente en el ángulo noroeste de la villa, ya que la llegada del ferrocarril, que bordeaba a la ciudad por el norte, hizo bascular hacia esta zona la vida de la urbe propiciando la creación en ella de un centro económico, comercial y financiero. Con esta operación, la antigua trama de esta parte de la ciudad se transformó con la apertura de calles como la de Claudio Marcelo, Cruz Conde, Avenida del Gran Capitán o la plaza de las Tendillas.

Por otro lado, con la demolición de la muralla ${ }^{7}$ en la segunda mitad del XIX, la ciudad inicia su definitiva expansión extramuros, superando progresivamente el antiguo recinto histórico ${ }^{8}$.

Como podemos observar, este espíritu regeneracionista del urbanismo proviene en gran medida de la etapa anterior en la que se impuso la tarea de ampliar, regularizar y mejorar el aspecto de las calles y plazas del viejo casco urbano cordobés modificando el trazado de muchas de ellas o, en muchos casos, sometiéndolo a uno completamente nuevo. Empero debido al estancamiento económico y la casi inexistencia de un tejido industrial en consonancia con el de otras ciudades españolas, Córdoba no podrá contar con una verdadera normativa urbanística hasta el año 1884 en que se redacten y aprueben las ordenanzas municipales, actuándose hasta ese momento por medio de bandos de policía urbana que resultaban siempre imprecisos y fáciles de burlar por los particulares.

No hay que perder la perspectiva de que todo este conjunto de reformas que se van a acometer en nuestra ciudad no son, en gran medida, equiparables a las realizadas en las grandes urbes españolas debido a la escasa potencialidad económica de las arcas municipales y al débil ritmo demográfico cordobés; obstáculos graves pero no insalvables para una ciudad adormecida que aspira a asimilar las nuevas necesidades del incipiente modelo capitalista y demográfico. Para ello, el modelo de expansión que seguirán las autoridades locales en este periodo -1868-1885- no será extramuros - aunque se seguirán derribando lienzos de muralla- sino intramuros, lo que provocará el hacimiento de los, cada vez más, numerosos habitantes de la ciudad y a su vez una segregación clasista materializada en la diferenciación espacial ${ }^{9}$.

7 Según MARTíN LÓPEZ, C., las causas del derribo del lienzo de muralla en nuestra ciudad no fueron las mismas que en otras ciudades, caso de Madrid o Barcelona que se debió a un fenómeno expansivo, sino que se debieron a una serie de factores más localistas: 1- Prevenciones higiénicas, 2- La llegada del Ferrocarril. 3- Periodos de carestía en los que los trabajos de derribo servian para dar trabajo a los más necesitados. 4- Inutilidad como cerco fiscal para el cobro de impuestos. La desaparición de las murallas, El Pregonero, diciembre de 1989, p.13.

8 VALVERDE FERNÁNDEZ, F., Las plazas del casco histórico de Córdoba, Córdoba 2007, pp. 20-21. Véase también CUENCA TORIBIO, J. M., Historia de Córdoba ..., pp. 143-144.

${ }^{9}$ SICA, P., Historia del urbanismo. El siglo XIX., Madrid 1981, vol. I, pp. 39-40. 
Será a finales de siglo cuando Córdoba empiece a propagarse extramuros derribándose, salvo algunos lienzos, la totalidad de la muralla. Según C. Martín López, su finalidad no fue estrictamente por necesidad, sino más bien fruto de la aplicación de criterios artísticos y técnicos equivocados a la hora de valorar su monumentalidad y a la falta de alternativas acertadas ${ }^{10}$.

Desde luego el panorama urbanístico que se abría ante los ciudadanos que la visitaban era desolador, más aún cuando la historia contaba los parabienes del esplendor que en otros tiempos había gozado la urbe califal. No es de extrañar que multitud de viajeros ${ }^{11}$ románticos dejarán en sus escritos para la posteridad la constatación de su decadencia; el inglés Jardine escribió:

Córdoba no presenta ahora más que un aspecto pobre y melancólico, y parece sumida en la indolencia, la suciedad, las ruinas, la miseria y los conventos. El palacio de Almanzor se ha convertido en el de la inquisición, es decir, la parte que no está en ruinas.

Con el mismo desencanto se expresaba Ponz cuando describía la Córdoba de 1792:

Esta ciudad, pues, docta, opulenta y rica desde su primer cuna, como podemos colegir, se ve ahora sin aquella opulencia, despoblada, y pobre quanto puede serlo qualquiera otra que carezca de tantas ventajas como el Autor de la naturaleza ha derramado en su ameno territorio. No hay fábricas, ni otro género de industria. Los catorce mil vecinos que tenía en tiempo de Rodrigo Méndez de Silva, como él asegura en su Población de España, esto es, a mediados del siglo pasado, se han reducido a los ocho mil escasos que he dicho a $V$. ¿En dónde están las brillantes telas de seda que aquí se labraban en el tiempo referido, los finisimos paños que se texían, los curiosos guadamecies que se transportaban a otras partes? ¿Ni de qué sirven las minas de plata, y de otros metales en la inmediata sierra morena, quando la Ciudad está llena de gente pobre y sin ocupación?

Este es un mal muy grande que irá a peor, si no se pone un pronto y rápido remedio, y sería lástima que con el tiempo viniese a reducirse la famosa Córdoba a un Villorrio desdichado... No debe sufrir tanta nobleza distinguida, como hay en Córdoba, los ricos mayorazgos, y

\footnotetext{
${ }^{10}$ Córdoba en el siglo XIX: Modernización de una trama histórica, Córdoba 1990, p. 235.

${ }^{11}$ Todos estos testimonios y algunos más de viajeros románticos están recogidos por LÓPEZ ONTIVEROS, A., en La imagen geográfica de Córdoba y su provincia en la literatura viajera de los siglos XVIII y XIX, Córdoba 1991; La ciudad de Córdoba: origen, consolidación e imagen, Servicio de Publicaciones Universidad de Córdoba, Córdoba 2009, pp. 133-201.
} 
Eclesiásticos que muy bien pueden coadyuvar con sus rentas que se diga y se publique en libros como lo hemos visto no hace mucho, ser su ciudad una de las más pobres y atrasadas de España, a pesar de tantas excelencias con que la ha favorecido la naturaleza, sin más ingeniatura, que la de algunas bayetas que se labran ni otro tráfico que el enviar fuera aceitunas embarriladas.

Por último, expondremos el testimonio del francés Poitou que a finales de siglo seguía recalcando la contraposición entre el esplendor árabe y la decadencia actual decimonónica:

De esta gloria, de estos esplendores, de estos de esta vida política y culta de otros tiempos -que precedentemente ha evocado- apenas quedan vestigios. Córdoba es hoy una ciudad muerta. Ella tenía antiguamente doscientos mil habitantes, hoy le quedan cuarenta mil. La hierba brota en las calles silenciosas; la mitad de las casas parecen desiertas".

\section{LAS TRANSFORMACIONES ACOMETIDAS 1868-1885}

Como anteriormente aludimos, hasta 1884 no hubo una normativa urbanística municipal que regulara de manera conjunta las diferentes transformaciones a realizar en el damero urbano y, por supuesto, que racionalizara el espacio previendo las necesidades futuras. Hasta ese momento la pauta de actuación municipal en el planímetro cordobés la marcaba las carestías más inmediatas: derribos, paro elevado, derrumbamientos, epidemias... en definitiva, hechos concretos sin ningún tipo de programación futura que, hasta bien entrado el siglo XX ocasionaran más de un problema en la construcción de nuevas parcelas extramuros por la falta de previsión de la municipalidad en este periodo.

Muchas son las obras que se llevaron a cabo en estos 17 años. A continuación, estudiaremos las que, a priori, fueron más relevantes para el desarrollo urbanístico de la urbe califal:

\subsection{Alineación, configuración y reforma de calles}

1. Paseo de la Ribera: Es uno de los lugares más antiguos para el recreo y esparcimiento de la ciudad. Era una de las zonas más frecuentadas por los cordobeses para sus jornadas de festejo ${ }^{12}$. En sus inmediaciones, existía una

\footnotetext{
12 "Los cordobeses de la época tenían por costumbre, los domingos de sol, dar un paseo e ir hacia los Arenales parándose a tomar un refresco en las ventas del camino. Así lo recoge la prensa local: «El remedio se impone: Esta tarde, siguiendo las corrientes más modernas, será
} 
incipiente infraestructura del ocio con tabernas donde poder degustar bebidas y viandas, un paseo plantado de álamos que acogían largos paseos a la sombra y zonas destinadas para el baño. No es de extrañar que este enclave fuera de especial relevancia para las autoridades locales ${ }^{13}$ que preocupados por las demandas del público que lo frecuentaba emprendía constantes obras de remodelación y mejora.

No obstante, según describe López Ontiveros ${ }^{14}$, las reformas del paseo de la Ribera no solo se debieron a cuestiones ociosas, sino que en gran medida eran de imperiosa necesidad a causa de la grave amenaza que suponían las periódicas crecidas del río Guadalquivir que ocasionaban violentas inundaciones en los barrios intramuros limítrofes a la orilla derecha y en el Campo de la Verdad al margen contrario.

Es por ello que desde finales del siglo XVIII se emprendió la tarea de construir un murallón que contuviera dichas crecidas, finalizando las obras a mediados del XIX con la construcción de un trozo coronado de 64 varas lineales en la muralla ${ }^{15}$ que supusiese, a su vez, una ampliación del paseo y dotar a Córdoba de un nuevo eje principal de tráfico que acogería la desviación de la carretera Madrid-Cádiz.

En 1868, con motivo de la petición de un vecino del paseo, empezaron las obras de alineación, aumentando la anchura ( 20 metros) en el tramo que iba desde la Iglesia de la Ajarquía hasta la Cruz del Rastro. A la altura de 1882 los trabajos de construcción y alineación continuaban con la demolición, previa expropiación de casas particulares ${ }^{16}$ con el objetivo de ganar desahogo espacial con el derribo de los $277,8 \mathrm{~m}^{2}$ que suponían un corral y una casilla que obstaculizaban el tránsito.

2. Ronda de los Tejares: En la actualidad es una de las arterias principales de la capital cordobesa. Su importancia sobrevino a raíz de la apertura de la

la carretera de los Arenales el obligatorio paseo de millares de personas que aprovechan [...]". SÁNCHEZ DE MIGUEL, A., Córdoba 1898: generación e historia: pérdida de las islas de Cuba, Filipinas, Puerto Rico, Marianas y Carolinas, Córdoba 1998, p. 17.

13 "Reclamando el deseo público de que el paseo de la Ribera se habilite con las conveniencias de otros años en alumbrado y riego, para que este centro de recreo pueda frecuentarse recomendándolo más el establecimiento de baños, se acordó pasar las órdenes a D. Antonio Moñino respecto al riego, peones camineros, sobre el arreglo del pavimento y empresario del gas sobre el alumbrado, auxiliándolo en lo que tuviera necesidad para la colocación de los postes o faroles". AMCO. , A.C., sesión del 6/08/1873, pp. $261 \mathrm{v}^{\mathrm{a}}-262$.

${ }^{14}$ Evolución urbana de Córdoba y de los pueblos campiñeses, Córdoba 1973, pp. 61-63.

${ }^{15}$ AMCO, Memoria presentada por el Alcalde Corregidor conde de Hornachuelos el 24 de marzo de 1852 a los señores de la Comisión especial del Murallón, Sec. 4, Leg. 3, Exp. 17.

${ }^{16}$ AMCO., A.C., sesión del 9/10/1882, s.f. 
estación ferroviaria y el basculamiento de la ciudad hacia el norte como consecuencia de las transformaciones que el nuevo medio de transporte proporcionaba a la ciudad.

En torno a 1880, debido a los problemas que ocasionaba restaurar el lienzo de muralla a los propietarios de las fincas colindantes a la Ronda, el Ayuntamiento aprobó un proyecto de alineación ${ }^{17}-15$ de noviembre de 1880 - como respuesta a la multitud de solicitudes ciudadanas para el derribo del tramo con vistas a poder tener una entrada a sus casas por la Ronda.

El plan de alineación tenía como objetivo marcar las pautas de la calzada ante las nuevas y futuras construcciones pues la importancia que iba adquiriendo era cada vez mayor. El proyecto fijaba una anchura uniforme de 28 metros desde la intersección con el Paseo de la Victoria hasta el Campo de la Merced.

A través de la prensa podemos considerar como las obras de remodelación, a parte de la función práctica y de mejora, respondían al prestigio que iba adquiriendo la calle: Con el derribo de gran parte de la muralla, la población tiene que recibir un natural ensanche especialmente por el lado de los Tejares. Convenientemente será pues que en esta parte se hagan alineaciones con toda escrupulosidad a fin de que no sea necesario después hacer innovaciones con perjuicio de los propietarios y del público ${ }^{18}$. A este respecto hay que añadir que las nuevas edificaciones albergaban fachadas muy ornamentadas cuyo fin era el de embellecer el paisaje por lo que el derrumbe de la muralla no fue un proceso traumático, como bien deja claro la municipalidad al acordar en sesión del 26 de febrero de 1883 dar autorización a D. Manuel García Lovera para la demolición de un antiguo torreón lindante con su propiedad ${ }^{19}$.

3. Calle Diego León: La Corporación estimó necesario aumentar la anchura de una de las calles más céntricas y concurridas tanto en peatones como en carruajes. Su localización entre dos grandes vías: la calle Duque de Hornachuelos y Alfonso XIII, su proximidad al centro urbano, el beneficio a la hora de aliviar el tráfico y, por supuesto, el embellecimiento de los edificios allí ubicados como el Instituto General y Técnico y la fonda suiza ${ }^{20}$; fueron directrices más que suficientes para que se presentara un proyecto de alineación y ensanche de la calle en 1891.

\footnotetext{
${ }^{17}$ AMCO., A.C., sesión del 15/11/1880, f. 540 y va

18 DIARIO DE CÓRDOBA, 21/12/1880; véase también las tiradas de los días 2/06/1881; 3/05/1882.

${ }^{19}$ AMCO., A.C., s.f.

${ }^{20}$ Diario de Córdoba, 21/06/1879.
} 
4. Calle Letrados: Era una de las vías más concurridas de la capital cordobesa a finales del siglo XIX por su naturaleza comercial y ser nexo entre el centro de la ciudad y varias parroquias. Uno de los graves inconvenientes, como en casi todas las calles del entramado urbano, era su angostura, ocasionando frecuentes accidentes de carruajes, sobre todo, los de mayores dimensiones acarreados por bueyes, y colapsando el tráfico de la vía, con las consiguientes molestias para los comercios allí ubicados ${ }^{21}$.

El mayor problema con el que se encontró el Consistorio a la hora de llevar a cabo el proyecto fue el económico. Una de las premisas que se le concertó -22 de septiembre de 1879- al arquitecto Felipe Sainz fue la de reducir al máximo los costos en las expropiaciones de fincas, pues en un primer momento el estudio preveía la destrucción de la línea de fachada de al menos 17 fincas.

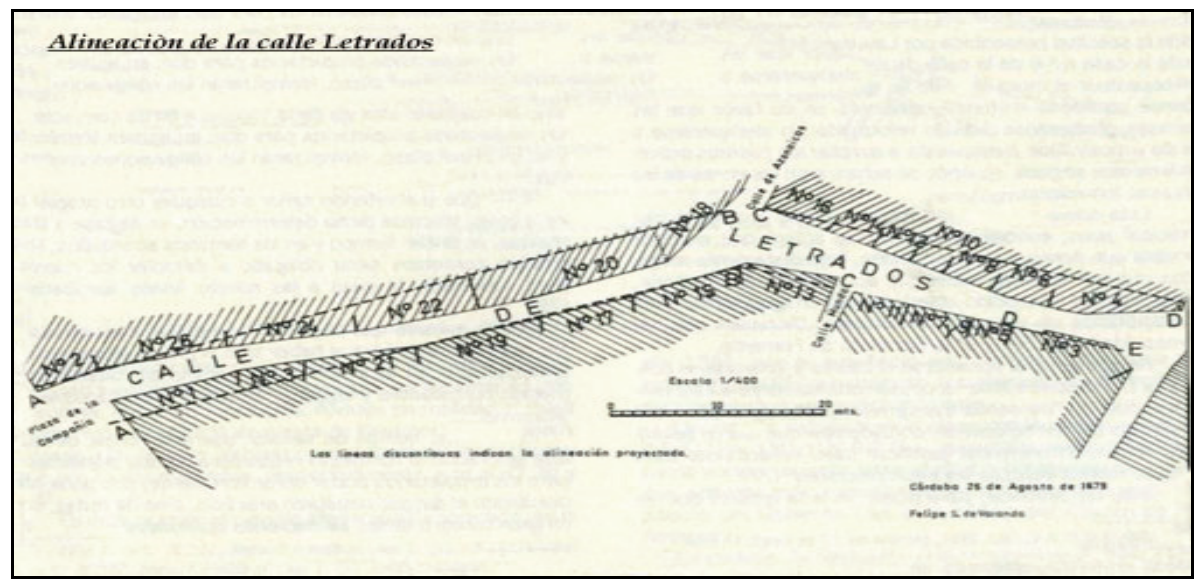

Fuente: MARTÍN LÓPEZ, C., Córdoba en el siglo XIX..., p. 395.

5. Calle Claudio Marcelo: El Ayuntamiento de esta capital ha tomado en consideración el proyecto de abrir una nueva calle que, partiendo de la del Ayuntamiento frente a la Espartería, desemboque frente al café del Recreo, cuyo proyecto está enlazado con el de levantar una gran fachada a las Casas Consistoriales en esa calle nueva. Para conseguir este objeto se acordó en

21 “[...] Bien comprendemos que nuestro pueblo agrícola necesita hacer esos transportes y que no debe ponerse a los labradores, clase respetabilísima obstáculos de ninguna clase; pero en las fachadas de la calle Letrados están las muestras de los destrozos causados, no sólo ayer sino otros días, y todos ven muy a menudo obstruido el tráfico, durante algunas horas, de aquella importante vía [...] creemos muy oportuno que cuando el Ayuntamiento que tanto á mejoras públicas se dedica, tenga la posibilidad de ello, no olvide la conveniencia del ensanche de la calle de Letrados", Diario de Córdoba, 20/02/1879 y 09/06/1880. 
la última sesión incoar el oportuno espediente, y se sacará a concurso la formación de planos de dependencias y demás necesario para este importante objeto $^{22}$. Cómo bien refleja la cita del diario local, el proyecto pretendía abrir una nueva vía que uniera la calle del Ayuntamiento y Arco del Real aprovechando las obras que se estaban realizando en el nuevo edificio capitular. La nueva sede de 4.330,77 $\mathrm{m}^{2}$-casa palacio del Duque de Hornachuelos- fue comprada por 225.000 ptas. el 6 de enero de 1877 e inmediatamente se mandó celebrar pública subasta para la elaboración del proyecto de remodelación y adecuación de las nuevas instalaciones. El arquitecto encargado fue D. Francisco Sainz de Varanda que presentó los planos de la calzada el 11 de febrero de 1878.

La ciudad acogió de buen grado el inicio de las obras -junio de 1878- para la creación de esta nueva travesía pues aparte de dotar a la ciudad con nuevos elementos ornamentales facilitaba la comunicación entre la población de la villa Alta y Baja ${ }^{23}$.

En un principio el tramo estaba proyectado con unas medias que iban desde los 8 metros de anchura por 80 metros de longitud pero ante la magnitud del proyecto -el presupuesto superaba el millón de pesetas- las obras se paralizaron ${ }^{24}$ y se procedió a sacar a subasta las fincas expropiadas, con el fin de que la iniciativa privada ${ }^{25}$ acabase las obras, como así sucedería al comprar D. Francisco Montoro Ordoñez y D. Antonio Carrasco los solares ofertados para la edificación de cinco edificios cuya planta baja se dedicará al comercio con gran ventaja para este y para la población en general ${ }^{26}$.

6. Calle Madera Alta: El primer plan de alineación que data de 1861 - iba desde la calle Concepción hasta Pérez de Castro- quedó plasmado solamente en papel tras el estallido de la "Septembrina". Los vecinos de la vía ante la ausencia de obras fueron reedificando sin seguir ningún tipo de directriz municipal, por lo que, al retomar el proyecto -1 de septiembre de 1897- el arquitecto municipal Pedro Alonso tuvo que redefinir sobre el antiguo plano de 1861 la nueva realidad de la vía.

${ }^{22}$ Diario de Córdoba, 19/12/1877.

23 "Ayer fue entregada al Sr. Alcalde de esta capital una manifestación, cubiertas de numerosas firmas, hechas por los propietarios, comerciantes é industriales de la Espartería y sus alrededores al Ayuntamiento, facilitándole por el utilísimo proyecto indicado en el Diario y referente a la apertura de una nueva vía que ponga en comunicación la calle del Ayuntamiento con la del Arco del Real", Diario de Córdoba, 22/12/1879 y véase también la tirada del 26/01/1879.

${ }^{24}$ Ibidem, 29/04/1882.

${ }^{25}$ Ibidem, 24/08/1882.

${ }^{26}$ Ibídem, 19/09/1882., en este artículo se hace referencia a que el nombre de la calle nueva podría ser Claudio Marcelo, como finalmente se acordó en sesión capitular de 9/06/1884, pp. 385-388. 
7. Calle de la Pastora: Al igual que ocurre en muchas otras calles de Córdoba, el tiempo transcurrido entre la aprobación del plan urbanístico y su realización es en demasía extenso y, el resultado final, poco o nada tiene que ver con los planos originales. Uno de estos casos lo protagoniza la artería de la Pastora. En un primer momento la actuación municipal sobrevino tras la petición -febrero de 1882- de dos propietarios de una licencia para acometer la reedificación de sus viviendas. Aprovechando la solicitud, la municipalidad encargó al arquitecto municipal D. Amadeo Rodríguez el proyecto ${ }^{27}$ para llevar a cabo la alineación -10 de noviembre de 1883-. Aunque no será hasta principios del siglo XX -noviembre de 1908- cuando realmente se acometan las obras tras la aprobación de un nuevo proyecto.

8. Paseo del Gran Capitán ${ }^{28}$ : Inicialmente fue concebido como un bulevar con una franja central terriza de carácter peatonal delimitada por árboles, dos calles laterales por las que discurrir el escaso tráfico de la época, y amplias aceras. Constaba de dos tramos. El comprendido entre San Nicolás de la Villa y la actual Ronda de los Tejares se abrió en 1866; su prolongación hasta la actual Avenida de América tuvo lugar a partir de 1904, con el fin de completar la unión del casco histórico con la Estación que había sido inaugurada en 1859.

En el primer ramal, entre San Nicolás y San Hipólito, se alzó el convento de monjas Benitas y Bernardas de San Martín, fundado en 1635 sobre las casas de los Marqueses de Comares que fue suprimido en 1836, para la realización del paseo que conservó el nombre del precedente convento y se terminó en 1843. Diecisiete años más tarde se abrió la calle del Gran Capitán hasta los Tejares.

El 28 de abril de 1882 se aprueba el ensanche del Paseo $^{29}$ por unanimidad con las consiguientes expectativas para la población y la prensa ${ }^{30}$ que veían como poco a poco el sector noroccidental de la ciudad se abría con ornamentadas avenidas y ensanches a semejanza de las grandes capitales españolas. Pero una vez más, la falta de presupuestos y el desinterés de las clases más pudientes por el interés público en beneficio de los particulares aletargaron el proyecto, reduciendo las actuaciones en dicha vía a meras obras menores de embaldosado de aceras, plantación de árboles y subsanación de elementos estropeados ${ }^{31}$.

${ }^{27}$ GABINETE DE ORDENACIÓN URBANA, Leg. 3, expediente $\mathrm{n}^{\circ} 15$, 1882. s.f.

28 Vid. los rigurosos estudios realizados por GARCÍA VERDUGO, F.R., Producción y propiedad del suelo urbano en Córdoba. El sector del Gran Capitán (1859-1936), 1985 y Las propuestas de ensanche en la ciudad de Córdoba, Estudios Geográficos, 182-183 (1986) 149-172.

${ }^{29}$ AMCO, A.C., sesión del 28/04/1882, s.f.; Diario de Córdoba, 30/04/1882.

30 "La prolongación de la calle del Gran Capitán quedó acordada antenoche por el municipio. No podemos menos que congratularnos por ver en vías de realización unas obras que con más insistencia ha pedido la opinión pública y la prensa", Diario de Córdoba, 30/04/1882.

${ }^{31}$ AMCO, A.C., sesión del 30/07/1868, pp. 209v-210v. 


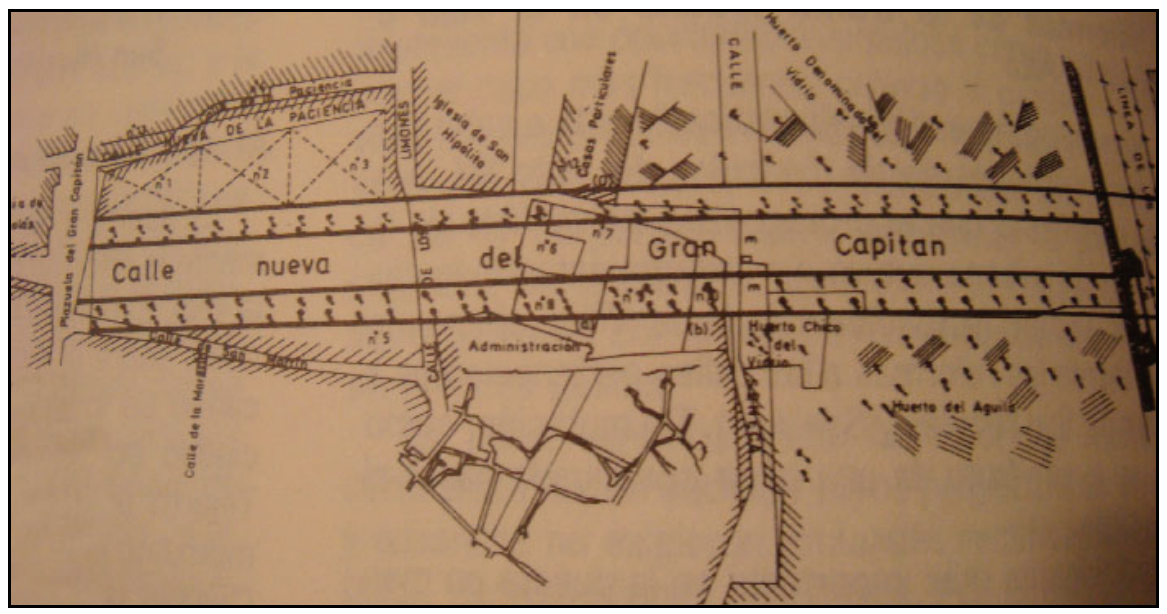

Fuente: MARTÍN LÓPEZ, C., “Córdoba en el siglo XIX...”, p. 426.

La continuación de la avenida se abrió, finalmente, entre 1904 y 1908 sobre terrenos del antiguo barrio de los Tejares y la zona meridional de la Huerta de la Reina. Varios edificios destacan en la zona, el palacete modernista esquina a Reyes Católicos, construido en 1907 y rehabilitado en 1984 para sede del Colegio de Arquitectos. También sobrevive en la misma acera, la casa número 22 que data de 1910. En 1917, se levantó el edificio del Banco Hispano. Otra casa interesante es la número 26, con fecha de 1925.

9. Calle Gondomar y Concepción: Existe en el centro de nuestra localidad precisamente frente a estas Casas Consistoriales, un grupo de edificaciones de tal extensión, que constituye quizá la mayor manzana de casas reunidas en el punto de más concurrencia y vida del vecindario. Circundado por las calles denominadas del Ayuntamiento, Espartería, Carreteras, Almonas o Gutiérrez de los Ríos, Huerto de San Andrés, calle de San Pablo y plaza del Salvador, reclama este gran perímetro una reforma beneficiosa que muy ventajosamente puede conseguirse con sólo dividirlo en cuatro secciones por dos amplias vías que lo crucen en su centro. Parece que las indiscutibles ventajas de esta útil mejora están favorecidas por el destino poco provechoso en verdad que tienen los terrenos existentes en el corazón de este perímetro, la mayor parte aplicado al cultivo, y cuyos propietarios cederán sin duda en muy reducido precio la extensión necesaria $[\ldots]^{32}$.

Lo que aquí recoge las Actas Capitulares del Consistorio cordobés es la profunda preocupación ante las nuevas realidades urbanísticas que se abrían a la urbe. Estamos ante un plan que pretendía unir de manera fluida dos grandes

\footnotetext{
${ }^{32}$ AMCO, A.C., sesión del 20/04/1882, s.f.
} 
zonas: Villa Alta y la Baja por medio de dos grandes vías capaces de absorber tanto las nuevas necesidades comerciales del vecindario como la fluidez del tránsito rodado. Un nuevo gran eje sería el que conectaría la puerta de Gallegos con la zona de la plaza de las Tendillas, y el siguiente ramal iría desde esta última hasta la plaza de la Constitución (cuyo nombre actual es de la Corredera), ampliando la construcción de la calle Claudio Marcelo hasta la intersección con Rodríguez Marín.

La calle de Gondomar es una de las calles comerciales principales de la ciudad de Córdoba. Antaño más tranquila, se convirtió en uno de los viales más importantes de la urbe tras la creación del Paseo de San Martín que comunicaba el centro de la ciudad con la Estación. Esta calle llegó a convertirse en una de las más transitadas, especialmente en el mes de mayo con la celebración de la Feria de Nuestra Señora de la Salud en el Paseo de la Victoria, por lo que permitía la afluencia de la toda la zona este de la ciudad (Centro y Axerquía).

Como una de las arterias principales del centro cordobés su mantenimiento y mejora fue clave para el desarrollo comercial de la zona por lo que la Corporación centró sus esfuerzos en la posibilidad de su ensanche. En 1871, se designó una Comisión que supervisara las tareas de expropiaciones de las casas afectadas por las obras. Las negociaciones con los propietarios no fueron más problemáticas de las que en un principio se preveían pues hasta cinco años más tarde no se consiguieron firmar las últimas escrituras de venta ${ }^{33}$.

Nueve años de tardanza -el proyecto de ensanche data del 18 de mayo de 1867- para concluir los trabajos que dotaran al centro cordobés de una vía amplía que pronto se benefició del empuje comercial dada su ubicación privilegiada. El progresivo crecimiento de la ciudad por el norte, gracias al empuje que supuso la construcción de la estación de FF.CC, hizo que las zonas comerciales también se desplazaran en el mismo sentido siendo la calle Gondomar una de las preferidas para el establecimiento de nuevos negocios.

La segunda fase para lograr un eje vertebrador era el saneamiento de la calle Concepción para unir la plaza de las Tendillas con la zona de los Jardines de la Victoria. Con tal motivo el 14 de octubre de 1879 el Ayuntamiento mandó rectificar los planos aprobados en 1867, ajustando la línea de ensanche a la nueva planimetría quedando expropiadas las casas 40, 45 y 47 , y los trabajos de ampliación terminados en 1882.

${ }^{33}$ Está información la podemos encontrar documentada con minuciosidad en MARTÍN LÓPEZ, C., Córdoba en el siglo..., p. 438. 
Con la apertura del primer tramo de la calle, en 1887 se empiezan a realizar nuevas actuaciones con el derribo del convento de la Concepción para la construcción de 11 viviendas y la apertura de un nuevo ramal que enlazara con esta. El propietario del inmenso solar que ocupaba el convento donó a la ciudadanía la titularidad de la calle con la única condición de sufragar con el erario público los gastos de empedrado y alumbrado propuesta que el Ayuntamiento aceptó de muy buen grado.

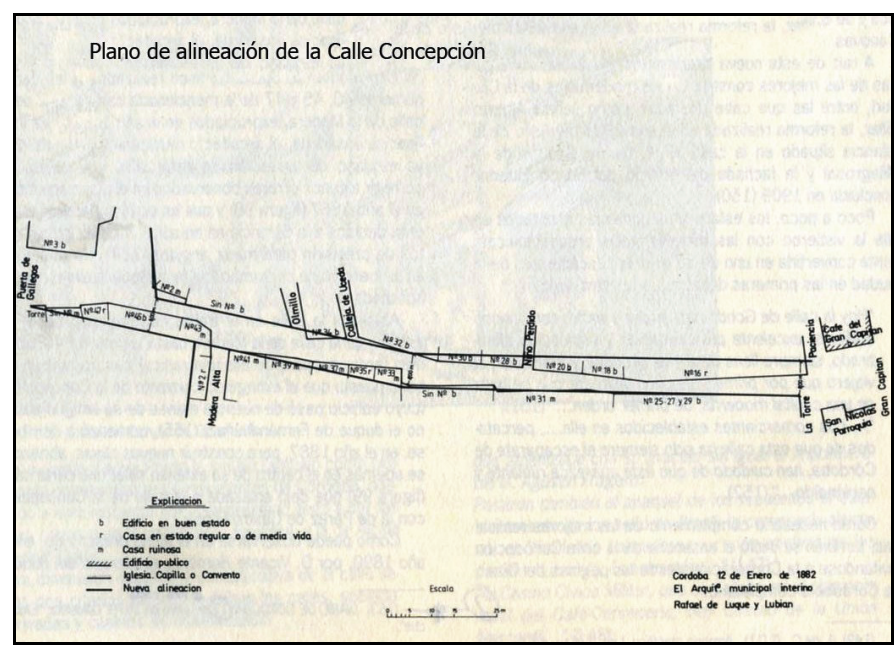

Fuente: Gabinete de ordenación urbana. Leg 1 Exp. $n^{\circ} 31.1882$.

10. Calle del Cuerno: Estrecha calle peatonal que une la plaza de San Juan con la de Ramón y Cajal. Con su alineamiento se pretendía cerrar otro eje vertebrador de la ciudad por su unión al Paseo del Gran Capitán y su salida a la estación del ferrocarril. La prioridad máxima que el Consistorio transmitió a la Comisión de Fomento era la de ensanchar la vía para facilitar el paso libre de carruajes en ambas direcciones para obtener además un beneficio económico rebajando el precio de los edificios a expropiar.

Desde este planteamiento se recomendaba la formación de un nuevo proyecto, que partiendo de la plazuela de San Felipe comprendiera la alineación de las calles de Argote (nombre actual de la vía) y de la Pierna hasta su salida a la calle Pedregosa, ampliándose así, en parte, el antiguo plan de 1863.

Sin lugar a dudas, los objetivos perseguidos son los mismos que los anteriores. Lo que sí era novedad era la intención que se manifiesta de conjugar el esquema de alineación y ensanche con un mayor respeto a la estructura preexistente a fin de minimizar las expropiaciones. 
Como vamos constatando, los escasos recursos del Municipio, le obligan, en este último período del siglo, a ir claudicando en sus antiguos esbozos, suavizándose así su obsesión por la línea absolutamente recta y conformándose sólo con dar a las calles la anchura que permitiese un tránsito holgado. Así pues, aunque de forma en gran medida forzada, fue madurando con el tiempo su política de regulaciones públicas.

Además, para poder reducir al mínimo el coste del proyecto proponía dos líneas alternativas, la primera, marcada en el plano con trazo grueso y continuo era en opinión del arquitecto, desde el punto de vista económico la más ventajosa, al ocupar menor cantidad de terreno de propiedad particular, pero en contrapartida dejaba en el extremo Norte de la calle un ángulo muy pronunciado; la segunda solución que presentaba únicamente variaba, con respecto a la primera, en el tramo expresado, para el cual proponía una alineación recta, señalada con trazos gruesos discontinuos, aunque su realización aumentaría notablemente el coste de las expropiaciones.

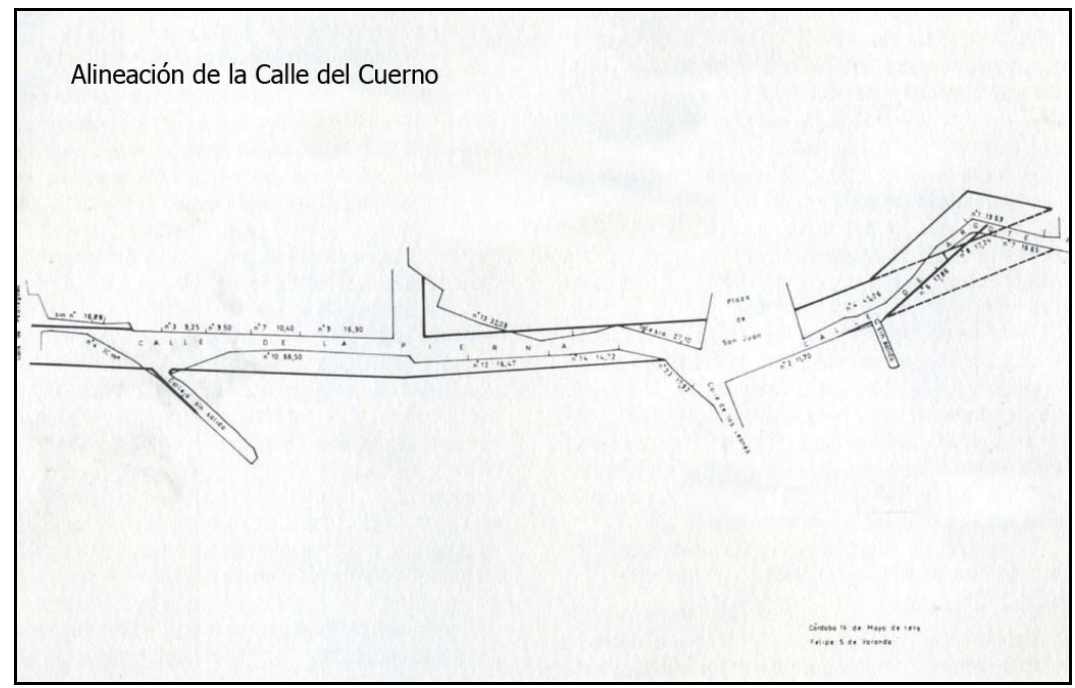

Fuente: Gabinete de ordenación urbana. Leg. 1 Exp. $n^{\circ} 32.1882$.

Examinado el plano por la Comisión de Fomento se decidió en función de la gran importancia de la vía principalmente para el tránsito de carruajes desde la parte baja a la alta de la población por la segunda opción, que proporcionaba a la calle una mayor rectitud y evitaba la formación de ángulos pronunciados. Aceptado pues, el dictamen por el pleno municipal quedó aprobado el proyecto el día 3 de mayo del referido año. 
Cabe señalar, sin embargo, que tampoco en esta ocasión tuvo aplicación práctica el proyecto y, prueba de ello es que en 1903 vuelve a plantearse la idea formándose un nuevo plan de alineación para la calle de la Pierna por considerarse en palabras del arquitecto, la alineación aprobada en el año 1879, ilusoria e irrealizable en la práctica, reduciéndose el ancho de esta calle a sólo 6 metros, para armonizar los intereses del Municipio con los de los propietarios. Con el mismo fin, en el año 1915, se optó por la alineación quebrada propuesta en 1879 para la calle Argote reduciéndose igualmente su anchura a 6 metros.

11. Calle Campanas: Tras la remodelación de la calle Pastora, en 1897, se acometió el proyecto para ensanchar la actual vía de Sánchez de Feria para mejorar el paso de carruajes con dirección a la Puerta de Almodóvar y aprovechar la situación ruinosa del Cuartel militar de la Trinidad ${ }^{34}$ para facilitar los trámites de las expropiaciones necesarias. El 25 de agosto de 1897 el Arquitecto municipal D. Pedro Alonso, presentaba el proyecto que resumía en las siguientes actuaciones.

Descartar el trazado recto de la alineación para evitar el costo total de las expropiaciones, sanear el trozo de Cuartel que linda con la Iglesia pues es foco de infecciones. Actualmente la calle se extiende hasta las mismas puertas de la Judería, y desemboca en la calle Fernández Ruano. A mitad de la calle se ensancha una placita conocida con el nombre de plaza del Profesor López Neyra, donde encontramos el antiguo palacio de los Guzmanes, reconvertido hoy en Archivo municipal.

\section{CONCLUSIONES}

La enseñanza de la historia local alentará a la exploración histórica del entorno por parte del alumnado, activando el interés por las ciencias sociales y su construcción. Por este motivo, en esta propuesta didáctica de práctica educativa hemos querido exponer la fundamentación teórica como punto de partida a la hora de realizar experiencias académicas para el alumnado de la asignatura de Didáctica de las Ciencias Sociales en el Grado de Educación Primaria.

Las documentaciones presentadas son fruto de una metodología colaborativa entre dos disciplinas como la Historia y la Didáctica de las Ciencias Sociales. En un primer momento, la función del profesorado estaría encaminada a guiar al alumnado en la elaboración del dossier histórico recogiendo la información que

\footnotetext{
${ }^{34}$ AMCO, A.C., sesión del 2/04/1891, s.f.
} 
crea más conveniente para el tipo de práctica que pueda plantearse: Itinerario didáctico, exposiciones, comparativas pasado-presente a través de imágenes...

En este punto, cabe reseñar que el adiestramiento en las técnicas propias de los historiadores resulta del todo interesante para la formación de los futuros docentes de Primaria.

Esta metodología nos permite incentivar la transversalidad y el trabajo en equipo entre las disciplinas implicadas. La realización de actividades de tipología como la presentada nos permitirá tratadas las competencias, no solo las inherentes a las áreas trabajadas, sino que también podrán fomentarse las digitales, sociales y cívicas... fruto del trabajo teórico-práctico del alumnado.

De este modo, el alumnado podrá tener los instrumentos necesarios para la adquisición de competencias propias del pensamiento histórico, social y crítico, a la vez que poco a poco irá asimilando la complejidad propia de la construcción de las dinámicas históricas, estableciendo su propia representación de la historia.

Por último, la enseñanza de la historia local ayuda que el estudiantado tena más interés por las Ciencias Sociales y la Historia, ya que siente más cercanos los procesos históricos que se han desarrollado en su localidad, la que conoce y con la que se identifica.

\section{BIBLIOGRAFÍA}

- ÁLVAREZ GUTIÉRREZ, L., La revolución de 1868 ante la opinión pública alemana, Madrid 1976.

- ÁlVAREZ JUNCO, J., La Comuna en España, Madrid 1971.

- ÁLVAREZ JUNCO, J., La ideología política del anarquismo español, 18691910, Madrid, 1976.

- ARÓSTEGUI, J., El carlismo alavés y la guerra civil, 1870-1876, Vitoria 1970.

- ARTOLA, M., La burguesía revolucionaria, 1808-1874, Madrid 1974.

- ARTOLA, M., Partidos y programas políticos, 1808-1936, Madrid 1974, 2 vols.

- BAHAMONDE MAGRO, A., y TORO MÉRIDA, J., Burguesía, especulación y cuestión social en el Madrid del siglo XIX, Madrid 1978. 
- BAHAMONDE, A., y MARTÍNEZ, J.A., Historia de España. Siglo XIX, Madrid 1994.

- BALLBE, M., Orden público y militarismo en la España constitucional, 1912-1983, Madrid 1983.

- BARREIRO, X.R., Historia contemporánea de Galicia, La Coruña 19821984, 4 vols.

- BERNAL, A.M., La propiedad de la tierra y las luchas agrarias andaluzas, Barcelona 1974.

- CORCUERA, J., Orígenes, ideología y organización del nacionalismo vasco. 1876-1904, Madrid 1979.

- COSTAS COMESAÑA, A., Apogeo del liberalismo en la Gloriosa. La reforma económica en el Sexenio liberal, 1868-1874, Madrid 1988.

- DÍAZ DEL MORAL, J., Historia de las agitaciones campesinas andaluzas, Madrid $^{3} 1979$.

- DONEZAR, J., La Constitución de 1869 y la revolución burguesa, Madrid 1985.

- EIRAS ROEL, A., El Partido Demócrata Español, 1849-1868, Madrid 1961.

- ESPADAS BURGOS, M., Alfonso XII y los orígenes de la Restauración, Madrid 1975 (reed. Madrid, 1990).

- ESPIGAdO TOCINO, G., La Primera República en Cádiz. Estructura social y comportamiento político durante 1873, Jerez-Sevilla 1993.

- LÓPEZ CORDÓN, M.V., La revolución de 1868 y la I República, Madrid 1976.

- LÓPEZ MORILLAS, J., El Krausismo español, Madrid 1980.

- LORENZO. A., El proletariado militante, Madrid 1974.

- MARTÍ GELABERT, F., La cuestión religiosa en la revolución de 1868 , Madrid 1989.

- MARTín NIÑO, J., La Hacienda española y la revolución de 1868, Madrid 1972. 
LAS TRANSFORMACIONES URBANÍSTICAS COMO RECURSO PEDAGÓGICO... 507

- MARTÍNEZ CUADRADO, M., Elecciones y partidos politicos en España, 1868-1931, Madrid 1969, vol. I.

- VERGES MUNDO, O., La Primera Internacional en las Cortes de 1871, Barcelona 1964.

- VILAR, J.B., El Sexenio democrático y el Cantón Murciano, 1868-1874, Murcia 1983.

- VILLACORTA BAÑOS, F., Burguesía y cultura. Los intelectuales españoles en la sociedad liberal, 1808-1931, Madrid 1980.

- VILLARES, R., Historia de Galicia, Madrid 1985.

- ZABALA, I. M., Románticos y socialistas, prensa española del XIX, Madrid 1972. 
